\title{
Deskripsi Sikap Sosial IPA, Normalitas Ilmuan, Kesenangan Belajar IPA, dan Ketertarikan Menambah Waktu Sosial IPA
}

\author{
Eko Wijayanto ${ }^{1}$ \\ ${ }^{1}$ SMP 49 Muaro Jambi, Jambi, Indonesia
}

\begin{tabular}{l} 
Article Info \\
\hline Article history: \\
Received Apr 1, 2020 \\
Revised Apr 15, 2020 \\
Accepted Apr 23, 2020 \\
\hline
\end{tabular}

Keywords :

Sikap

IPA

SMP

\begin{abstract}
ABSTRAK
Tujuan penelitian: Penelitian dilakukan di SMP 49 Muaro Jambi yang memiliki jumlah siswa sebanyak 23 orang siswa, penelitian ini sendiri bertujuan untuk mengetahui gambaran umum tentang deskripsi Sikap sosial IPA, Ketertarikan memperbanyak waktu belajar IPA, Normalitas Ilmuan pada siswa serta kesenangan bealajar IPA.
\end{abstract}

Metodologi: Adapun pendekatan yang peneliti gunakan dalam penelitian ini yaitu pendekatan kuantitatif dan penelitian survei merupakan jenis penelitian yang digunakan yaitu dengan mengggunakan instrumen penelitian berupa angket. Dan untuk analisis data menggunakan teknik teknik analisis statistik deskriptif.

Temuan utama: Hasil yang didapat dari penelitian ini adalah pada indikator sikap sosial IPA sebanyak 30,4\% yang sudah menerapkan sikap sosial IPA, Sebanyak $30,2 \%$ yang sudah menerapkan normalitas ilmuan, 39,1\% siswa yang ketertarikan meluangkan waktu belajar IPA dan sebanyak 52\% siswa senang Belajar IPA.

Keterbaruan peneltian: Dapat dilihat bahwa, dengan mengetahui sikap siswa didalam pembelajaran, maka guru mampu memilih metode pembelajaran yang efektif.

This is an open access article under the CC BY-NC license

Corresponding Author:

Eko Wijayanto

SMP 49 Muaro Jambi, Jambi, Indonesia

email: Ekow71257@gmail.com

\section{PENDAHULUAN}

Sikap adalah tindakan yang akan dilakukan oleh semua orang. Sikap adalah pandangan atau perasaan yang disertai kecenderungan untuk bertindak terhadap obyek tertentu. Sikap diperoleh melalui aktivitas "menerima, menjalankan, menghargai, menghayati, dan mengamalkan" [1]. Sikap merupakan bentuk persepsi seseorang terhadap suatu objek yang di gambarkan dengan ekspresi suka ataupun tidak [2]. Sikap terhadap IPA terkait dengan rasa suka atau tidak sukanya siswa terhadap mata pelajaran IPA [3]. Sikap siswa terhadap mata pelajaran IPA ada dua yaitu sikap positif dan negatif. Sikap positif ditandai dengan siswa cenderung tekun dalam belajar, sedangkan sikap negatif ditandai dengan siswa tidak bersemangat dalam belajar [4]

Sikap adalah sesuatu hal yang tidak akan pernah lepas dari makluk yang bernama manusia. yang menjelaskan bahwa Sikap sangat melekat dalam kehidupan sehari-hari dimana sikap sendiri merupakan pandangan atau perasaan yang disertai kecenderungan untuk bertindak terhadap obyek tertentu [5].Sikap akan diperoleh melalui berbagai aktivitas seperti menjalankan, menerima, dan lain sebagainya. Oleh karena itu proses pembelajaran menjadi penentu dari perkembangan sikap seseorang. perkembangan sikap itu sangat penting, jadi guru sebagai pendidik harus memastikan telah memberikan pengajaran yang baik dan tepat terhadap perkembangan sikap seorang siswa, dan sebagai pendidik sudah seharusnya diketahui bahwa, setiap individu memiliki sikap yang unik dan berbeda sehingga mengakibatkan sikap yang ada pada peserta didik pun beraneka ragam. 
Jika berbicara tentang sikap maka tidak akan pernah bisa dipisahkan dengan dunia pendidikan, Pendidikan merupakan hal yang sangat dibutuhkan oleh manusia, dan tidak akan pernah lepas dari pendidikan itu sendiri. Pendidikan merupakan upaya untuk menciptakan sumber daya manusia yang berkualitas, sehingga penting untuk meningkatkan pendidikan di Indonesia [6]. Pendidikan sangat dibutuhkan agar dapat membimbing peserta didik untuk menggapai cita-citanya melalui wawasan dan ilmu yang telah diberikan dari suatu pendidikan [7]. Sekolah sebagai lembaga pendidikan memiliki 2 tujuan utama yaitu sebagai tempat untuk menjadikan manusia yang memiliki akhlak yang baik serta menjadikan manusia tersebut juga pintar dalam segi pengetahuannya. Lembaga pendidikan memiliki tujuan untuk menyiapkan siswa atau peserta didik agar dapat bertahan hidup di masyarakat dan dapat membentuk karakter- karakter setiap individu agar sesuai dengan nilai-nilai yang berlaku masyarakat. Salah satu pembelajaran yang ada disekolah adalah pembelajaran IPA [8].

Dunia pendidikan menjadi tempat utama dalam memperbaiki sikap. Pendidikan merupakan tempat untuk memproses atau mempengaruhi orang yang berada didalamnya agar mampu menyesuaikan diri sebaik mungkin dengan lingkungannya, baik itu pada lingkungan keluarga, maupun lingkungan masyarakat sehingga akan menimbulkan perubahan dalam diri peserta didik [9]. Dinegara - negara maju seperti Amerika Serikat, Jepang, Cina, dan Korea sudah mulai menerapkan pendidikan karakter yang dimulai dari pendidikan dasar, yang saat ini mulai dicoba terapkan di Indonesia dengan diperlihatkannya [10]. Beberapa bukti bahwa implementasi pendidikan karakter yang diatur secara sistematis benar-benar memiliki efek positif terhadap prestasi akademik. Maka dari itu agar pendidikan sanggup memberi kontribusi yang terbaik terhadap kemajuan bangsa Indonesia maka sendi-sendi pendidikan nasional perlu ditranformasikan atau ditata kembali sedemikian rupa [11].

Tujuan dari penelitian ini adalah untuk mengetahui sejauh mana peserta didik dapat mengimplikasikan sosial IPA, sejauh mana siswa yang ada di sekolah tersebut tertarik untuk memperbanyak waktu untuk belajar fisika dan bagaimana sifat sifat siswa dalam memahami normalitas ilmuan, metode yang dilakukan dalam penelitian ini yaitu metode penelitian Kuantitatif, dengan rancangan penelitiannya yaitu Penelitian Survei yang bersifat deskriptif, dengan menggunakan pendekatan penelitian yang bersifat objektif, dan dalam pengujian menggunakan metode statistik .yang hasil dari penelitian yang diperoleh berupa angka pengelolaan pembelajaran baik itu motivasi siswa, keterampilan proses sains siswa [12].

\section{METODE PENELITIAN}

Pendekatan dalam penelitian ini menggunakan pendekatan kuantitatif. Suatu pendekatan penelitian yang bersifat objektif bisa diartikan sebagai pendekatan kuantitatif, dan dalam pengujian menggunakan metode statistic [12]. Pendekatan kuantitatif didapat dari hasil penelitian yang diperoleh berupa angka pengelolaan pembelajaran. Pada penelitian ini peneliti menggunakan jenis penelitian kuantitatif dengan menggunakan metode deskriptif [13]. Metode dekriptif digunakan untuk mendeskripsikan hasil penelitian secara rinci .

Penelitian kuantitatif dilaksanakan di Sekolah Menengah Pertama Negeri Negeri 9 Muaro Jambi, dengan jumlah total siswa sebanyak 23 orang siswa. Untuk mengumpulkan data variable bebas dan variable terikat menggunakan Instrumen angket/kuesioner yang diadopsi dari angket Astalini dan Kurniawan (2019) [14]. Pelaksanaan penelitian dilakukan menggunakan langkah - langkah sebagai berikut, yaitu: (1) menyusun indikator variabel penelitian; (2) menyusun kisi-kisi instrumen; (3) menyusun item; (4) melakukan uji coba instrumen; (5) melakukan uji validitas instrumen penelitian; (6) melakukan uji prasyarat analisis; (7) melakukan uji hipotesis.

Penelitian ini juga menggunakan jenis penelitian survei. Penelitian survei merupakan salah satu jenis penelitian yang pengambilan datanya menggunakan pertanyaan-pertanyaan tertulis, bukan pertanyaan lisan [15]. Selain itu penggunaan SPSS ini bertujuan untuk mengetahui berapa persen hubungan sikap kejujuran yang sudah ditanamkan pada peserta didik dalam proses Pembelajaran IPA. Dan juga ditambah dengan teknik analisis data dengan menggunakan library research (studi pustaka).

\section{HASIL DAN PEMBAHASAN}

\subsection{Implikasi Sosial IPA}

Sikap sosial IPA adalah suatu bagian yang sangat penting dan sudah seharusnya dimiliki oleh setiap peserta didik yang sedang mempelajari IPA disekolah, dimana Implikasi sosial IPA dapat membantu membentuk sikap siswa agar mandiri dan dapat bekerjasama dengan siswa lainnya dalam proses belajar dan mengajar dikelas. Selanjutnya dapat dipahami juga bahwa sikap implikasi sosial IPA harus ditanamkan kepada setiap individu yang dimulai semenjak dini ${ }^{(16)}$

Dengan menggunakan SPSS sebagai software pengelolah data digunakan untuk mendapatkan hasil dari penelitian ini tentang Implikasi sosial IPA, adapun hasil yang didapatkan yaitu: 
Tabel 1. Data karakteristik implikasi sosial IPA

\begin{tabular}{ccccccc}
\hline Variabel & Interval & Kategori Sikap & Frekuensi & $\begin{array}{c}\text { Persentase } \\
\%\end{array}$ & & \\
\hline & $8,0-14,41$ & Sangat Tidak Baik & 4 & 17,3 & Mean & 27.52 \\
Implikasi Sosial & $14.41-20,80$ & Tidak Baik & 5 & 21,7 & Median & 27 \\
IPA & $20,81-27,70$ & Cukup & 7 & 30,4 & Modus & 27 \\
& $27,21-33,60$ & Baik & 4 & 17,4 & Minimum & 23 \\
& $33,61-40,00$ & Sangat Baik & 3 & 13,0 & Maksimum & 37 \\
\hline
\end{tabular}

Berdasarkan data pada tabel 1 dapat dipahami bahwa dari total 23 orang subjek yang merupakan siswa SMP 49 Muaro Jambi didapatkan nilai Mean sebanyak 27.52, dan diketahui nilai tengah sebanyak (median) 27 dan nilai yang banyak keluar (modus) sebesar 27 dan sebanyak nilai minimal sebesar 23 dan maksimal sebesar 37 , dan sebanyak $17,3 \%$ siswa yang sangat tidak baik dalam mengamplikasi sikap sosial IPA, sebanyak $21,7 \%$ siswa yang tidak baik untuk mengaplikasikan sikap sosial IPA, 17,4\% siswa sdah baik dalam mengaplikasikan sosial IPA, dan siswa yang sangat mampu mengaplikasikan sosial ipa sebanyak $13 \%$

Dari tabel dapat disimpulkan bahwa masih banyak siswa yang belum bisa menerapkan Sikap Implikasi dengan jumblah persentasi sebesar 30,4\% dibandingkan dengan siswa yang belum bisa menerapkan sikap implikasi sosial IPA sebanyak 39,0\% siswa dan sebanyak 30,6\% siswa yang masih bingung apakah sudah menerapkan sikap implikasi sosial ipa atau belum.

Pada hasil penelitian sebelumnya menyimpulkan bahwa sikap siswa lebih dominan dalam kategori baik, dan siswa menunjukkan sikap yang positif terhadap sains pada kategori baik [15]. Maka pada penelitian hasil yang didapatkan yaitu para siswa tidak dapat mengimplikasikan sikap IPA, sehingga banyak siswa yang tidak memiliki sikap yang baik terhadap sikap IPA.

\subsection{Normalitas Ilmuan}

Normalitas ilmuan merupakan sikap yang harus dimiliki oleh seorang siswa yang sedang melakukan kegiatan pendidikan yang dimulai dari pendidikan dasar sampai ke perguruan tinggi.

Tabel 2. Data karakteristik normalitas ilmuan IPA

\begin{tabular}{ccccccc}
\hline \multirow{2}{*}{ Variabel } & Interval & $\begin{array}{c}\text { Kategori } \\
\text { Sikap }\end{array}$ & Frekuensi & $\begin{array}{c}\text { Persentasi } \\
\%\end{array}$ & \\
\hline \multirow{3}{*}{ Normalitas ilmuan } & $7,00-12,60$ & Sangat Tidak Baik & 4 & 17,4 & Mean & 23 \\
& $12,70-18,20$ & Tidak Baik & 4 & 17,4 & Median & 22 \\
& $18,30-23,80$ & Cukup & 8 & 34,8 & Modus & 22 \\
& $23,90-29,40$ & Baik & 4 & 17,2 & Minimum & 19 \\
& $29,50-35,00$ & Sangat Baik & 3 & 13,0 & Maksimum & 32 \\
\hline
\end{tabular}

Dari data diatas bisa diketahui masih banyak anak yang belum menerapkan normalitas ilmuan, hal ini bisa diketaui dari persentase yang sangat tinggi yaitu sebanyak 34,8\%. Sedangkan hanya sebanyak 30,2\% siswa yang sudah menerapkan normalitas ilmuan dan 34,8\% yang belum paham maksud dari normalitas ilmuan itu sendiri sehingga hanya menjawab dengan jawaban yang netral. Hal ini menandakan bahwa siswa sudah mengetahui bagaimana semestinya cara kerja dari ilmuan itu sendiri, ini sedikit berbeda dengan hasil penelitian sebelumnya yang menyatakan bahwa pesentase yang paling banyak adalah jawaban dari cukup yang menandakan bahwa siswa masih bingung untuk memahami bagaimana normalitas ilmuan itu seharusnya dan belum bisa melihat diri sendiri sebagai ilmuan [16]. Normalitas ilmuan yaitu bagaimana pandangan siswa terhadap para ilmuan, siswa berpandangan bahwa ilmuan adalah orang biasa yang menghabiskan waktunya di laboraturium $[17,18]$.

\subsection{Ketertarikan meluangkan waktu belajar IPA}

Setiap siswa pasti memiliki pelajaran favorit masing-masing yang dimana setiap siswa pasti berharap mata pelajaran yang mereka senangi tersebut ditambah waktunya untuk belajar. Ketertarikan meluangkan waktu belajar IPA menandakan bahwa siswa tersebut senang terhadap mata pelajaran IPA yang sedang ia pelajari. Dimana sikap positif siswa pada IPA tentunya juga dipengaruhi oleh kesenangan belajar IPA itu sendiri [18]. Sikap siswa terhadap mata pelajaran yang siswa sukai bisa dipengaruhi beberapa hal seperti dari faktor guru, lingkungan maupun pelajaran itu sendiri.

Untuk mengetahui persentase siswa yang tertarik meluangkan belajar IPA bisa dilihat dari hasil pengukuran dengan menggunakan sofware SPSS maka didapatkan data sebagai berikut:

Tabel 3. Data ketertariakan belajar IPA 


\begin{tabular}{|c|c|c|c|c|c|c|}
\hline Variabel & Interval & $\begin{array}{l}\text { Kategori } \\
\text { Sikap }\end{array}$ & Frekuensi & $\begin{array}{c}\text { Persentasi } \\
\%\end{array}$ & & \\
\hline Ketertarikan & $7,00-12,60$ & Sangat Tidak Baik & 4 & 17,4 & Mean & 25,39 \\
\hline meluangkan belajar & $12,70-18,20$ & Tidak Baik & 6 & 26,1 & Median & 35 \\
\hline \multirow[t]{3}{*}{ IPA } & $18,30-23,80$ & Cukup & 4 & 17,4 & Modus & 35 \\
\hline & $23,90-29,40$ & Baik & 2 & 8,7 & Minimum & 28 \\
\hline & $29,50-35,00$ & Sangat Baik & 7 & 30,4 & Maksimum & 45 \\
\hline
\end{tabular}

Dengan mengamati data pada tabel diatas diatas, maka akan diketahui bahwa ketertarikan siswa dalam meluangkan waktu terhadap pembelajaran fisika sangat banyak yaitu ada sebanyak $39,1 \%$ anak yang tertarik, dan siswa cukup banyak menjawab tidak mau meluangkan waktu dalam belajar IPA yaitu sebanyak $17,4 \%$ yang tidak tertarik meluangkan waktu untuk belajar IPA. Selebihnya siswa menjawab dengan jawaban netral atau cukup yaitu sebanyak 17,4\% dari total anak yaitu sebanyak 23 orang siswa, ini memberikan makna bahwa banyak siswa yang masih bingung akan jawabanya, ini sedikit berbeda dengan hasil penelitian oleh Astalini, yang menemukan bahwa ketertarikan siswa dalam belajar fisika dengan kata lain meluangkan waktu belajar IPA itu dalam kategori cukup, penyebabnya siswa lebih suka membaca ketika sudah dekat ujian dibandingkan hari-hari biasa. Sikap netral ini mengindikasikan bahwa masih sulitnya menumbuhkan keinginan meluangkan waktu belajar siswa [19-21].

\subsection{Kesenangan dalam Belajar IPA}

Banyak hal yang mempengaruhi kesenangan belajar IPA salah satu adalah dari bagaimana guru yang mengajar IPA, sehingga ada siswa yang senang dan ada siswa yang tidak senang belajar IPA. Untuk mengetahui hasil pengukuran dengan menggunakan sofware SPSS maka didapatkan data sebagai berikut:

Tabel 4 Data kesenangan belajar IPA

\begin{tabular}{ccccccc}
\hline \multirow{2}{*}{ Variabel } & Interval & $\begin{array}{c}\text { Kategori } \\
\text { Sikap }\end{array}$ & Frekuensi & $\begin{array}{c}\text { Persentasi } \\
\%\end{array}$ & \\
& $7,00-12,60$ & Sangat Tidak Baik & 2 & 8,6 & Mean & 34,48 \\
Kesenangan & $12,70-18,20$ & Tidak Baik & 5 & 21,7 & Median & 35 \\
belajar IPA & $18,30-23,80$ & Cukup & 4 & 17,3 & Modus & 35 \\
& $23,90-29,40$ & Baik & 6 & 26,0 & Minimum & 28 \\
& $29,50-35,00$ & Sangat Baik & 6 & 26,0 & Maksimum & 45 \\
\hline
\end{tabular}

Dengan mengamati data diatas, maka akan diketahui bahwa ketertarikan siswa dalam meluangkan waktu terhadap pembelajaran IPA sangat banyak yaitu ada sebanyak 52\% anak senang belajar IPA, siswa yang menjawab tidak senang dalam belajar IPA yaitu sebanyak 30,3\%. Selebihnya siswa menjawab dengan jawaban netral atau cukup yaitu sebanyak 17,3\% dari total anak yaitu sebanyak 23 orang siswa, ini memberikan makna bahwa banyak siswa yang masih memiliki rasa senang dalam belajar IPA, Hasil penelitian ini sejalan dengan hasil penelitian [5].

\section{KESIMPULAN}

Berdasarkan hasil penelitian yang telah dilakukan diatas dapat disimpulkan bahwa sebanyak sikap sosial IPA sebanyak 30,4\% yang sudah menerapkan sikap sosial IPA, Sebanyak 30,2\% yang sudah menerapkan normalitas ilmuan, dan 39,1\% siswa yang ketertarikan meluangkan waktu belajar IPA dan sebanyak 52\% siswa senang Belajar IPA. Jadi siswa tertarik meluangkan waktu untuk belajar IPA sangat banyak bahkan melebihi nilai setengah dari siswa yang ada dikelas tersebut. Tetapi indikator yang lainnya walaupun tidak sampai setengah dari siswa yang ada di sekolah tersebut tetapi terdapat siswa yang masih bingung terhadap indikator yang telah disebutkan diawal.

\section{UCAPAN TERIMA KASIH}

Peneliti mengucapkan terimakasih kepada seluruh responden yang telah bersedia dan seluruh elemen yang telah membatu, saya ucapkan terimakasih.

\section{REFERENSI}

[1] K. Hardianyanti., Astalini., dan D. A. Kurniawan, "Sikap Siswa Terhadap Mata Pelajaran Fisika Di Sma Negeri 5 Muaro Jambi”, Edu Fisika: Jurnal pendidikan fisika. 32. 2018 
[2] D.K. Kurniawan., Astalini., dan L. Anggraini, "Evaluasi sikap siswa SMP terhadap IPA di Kabupaten Muaro Jambi”. 2018

[3] R, Darmawangsa., Astalini., dan D.A. Kurniawan, "Pengembangan Instrumen Sikap Siswa Sekolah Menengah Atas terhadap Mata Pelajaran Fisika", Jurnal Pendidikan FisikaUniversitas Muhammadiyah Makassar, vol. 6, no. 1, pp. 11071114. 2018.

[4] A. Astalini., dan D. A. Kurniawan, "Identifikasi sikap implikasi sosial dari IPA, ketertarikan menambah waktu belajar IPA, dan ketertarikan berkarir dibidang IPA siswa SMP se-kabupaten Muaro Jambi”, Jurnal Tarbiyah: Jurnal Ilmiah Kependidikan, vol. 7, no. 2, pp. 93-108. 2018

[5] K. Hardiyanti., Astalini., dan D.A. Kurniawan, "Sikap siswa terhadap mata pelajaran fisika di SMA Negeri 5 Muaro Jambi”, EduFisika: Jurnal Pendidikan Fisika, vol. 3, no. 2, pp. 1-11. 2018.

[6] A. Asrial., Syahrial., dan D. A. Kurniawan, "Hubungan Kompetensi Pedagogik dengan Kompetensi IPA Mahasiswa Pendidikan Guru Sekolah Dasar”. Pedagogia: jurnal pendidikan, vol. 8, no. 2, pp. 149-157. 2019

[7] D.S. Putra., A. Lumbantoruan., dan S.C. Samosir, "Deskripsi sikap siswa: adopsi sikap ilmiah, ketertarikan memperbanyak waktu belajar fisika dan ketertarikan berkarir di bidang fisika", Tarbiyah: Jurnal Ilmiah Kependidikan, vol. 8, no. 2, pp. 91-100. 2019.

[8] D. Oktaviana, "Penerapan rpp berbasis multiple intelligences untuk meningkatkan aktivitas dan hasil belajar fisika siswa pada materi kalor dan perpindahan kalor kelas x mia 4 sma negeri 3 kota jambi”, Jurnal EduFisika, vol. 1, no. 1, pp. 7-12. 2016.

[9] S.A. Kamaruddin, "Character Education and Students Social Behavior”, Journal of Education and Learning, vol. 6, no. 4, pp. 223-230. 2012.

[10] Kemendikbud. Konsep dan Pedoman Penguatan pendidikan karakter Tingkat sekolah dasar dan sekolah menengah pertama. 2017.

[11] A. Hermawan., dan H.L. Yusran, "Penelitian Bisnis: Pendekatan Kuantitatif”, Depok: Kencana. 2017.

[12] Astalini \& D.A. Kurniawan. Pengembangan instrumen sikap siswa sekolah menengah pertama terhadap mata pelajaran IPA. Jurnal Pendidikan Sains (JPS).7(1). 2019

[13] D. A. Kurniawan., Astalini., L. Anggraini, "Evaluasi sikap siswa smp terhadap ipa di kabupaten Muaro Jambi”, Jurnal Ilmiah DIDAKTIKA, vol. 19, no. 1, pp. 124-139, 2018

[14] Astalini, "Sikap terhadap mata pelajaran ipa di SMP se-Kabupaten Muaro Jambi. Lentera pendidikan, vol. 21, no. 2, pp. 214-227. 2018

[15] D.A. Kurniawan., Astalini., N. Kurniawan. Sikap siswa terhadap pelajaran IPA di SMP Kabupaten Muaro Jambi Provinsi Jambi. Curricula: journal of teaching and learning, vol. 4, no. 3, pp. 111-127. 2019

[16] Astalini, D,A. Kurniawan., dan A.D. Putri, "Identifikasi Sikap Implikasi Sosial Dari Ipa, Ketertarikan Menambah Waktu Belajar Ipa, Dan Ketertarikan Berkarir Dibidang Ipa Siswa Smp Se-Kabupaten Muaro Jambi”, Jurnal Tarbiyah: Jurnal Ilmiah Kependidikan, vol. 7, no. 2, 2018

[17] Maison., Astalini., D. A. Kurniawan., R. Perdana., L. Anggraini, “The Phenomenon of Physicology Senior High School Education: Relationship of Students' Attitudes towards Physics, Learning Style, Motivation. Universal Journal of Educational Research. vol. 7, no. 10, pp. 2199-2207, 2019,

[18] R. Rahmayeni, "Kerja keras siswa dalam pelajaran sains”, Journal Evaluation in Education, vol. 1, no. 1, pp. 27-33, 2020

[19] M. Corry, "Identifikasi religiusitas siswa di sma adhyaksa 1 jambi", Journal Evaluation in Education, vol. 1, no. 1, pp. $15-20,2020$

[20] N. Neldawati, "Deskripsi lingkungan belajar siswa terhadap mata pelajaran fisika di sma ferdy ferry putra kota jambi”, Journal Evaluation in Education, vol. 1, no. 1, pp 1-7, 2020

[21] S. Hasrani, "Kreativitas siswa dalam mata pelajaran ipa", Journal Evaluation in Education, vol. 1, no. 1, pp. 21-26, 2020 